\title{
Some Analyses of Erdős Collaboration Graph
}

\author{
Vladimir Batagelj* and Andrej Mrvar \\ University of Ljubljana
}

\begin{abstract}
Patrick Ion (Mathematical Reviews) and Jerry Grossman (Oakland University) maintain a collection of data on Paul Erdős, his co-authors and their co-authors. These data can be represented by a graph, also called the Erdôs collaboration graph.

In the paper some techniques for analysis of large networks (different approaches to identify 'interesting' individuals and groups, analysis of internal structure of the main core using pre-specified blockmodeling and hierarchical clustering) and visualizations of their parts, are presented on the case of Erdős collaboration graph, using program Pajek.
\end{abstract}

Keywords: large networks, cores, visualization, clustering, blockmodeling

Math. Subj. Class. (1991): 92H30, 93A15, 68R10, 05C90, 92G30, 62H

*The corresponding author: Vladimir Batagelj, University of Ljubljana, FMF, Department of Mathematics, Jadranska 19, 1000 Ljubljana, Slovenia. e-mail: vladimir.batagelj@uni-1j.si 


\section{Introduction}

The current level of development of computer technology allows us to deal with large (having thousands to several hundreds of thousands of lines - arcs and/or edges) networks already on PCs. The basic problem is that such networks can't be grasped in a single view - we have to either produce a global view/characteristics omitting the details, or make a detailed inspection of some selected part of the network of moderate size (some tens of vertices), or something in between. The Erdős collaboration graph is an example of a large network on which we can present some techniques that can be used for analysis of large networks. The obtained results are of their own interest for graph theory community.

Paul Erdôs was one of the most prolific mathematicians in the history, with more than 1500 papers to his name. He was born March 26, 1913 in Budapest, Hungary and died September 20, 1996 in Warsaw, Poland. Paul Erdős won many prizes including Cole Prize of the American Mathematical Society in 1951 and the Wolf Prize in 1983. He is also known as a promoter of collaboration and as a mathematician with the largest number of different co-authors. This was a motivation for the introduction of the Erdôs number.

\section{Erdôs collaboration graph}

The Erdös number $\mathbf{n}_{E}$ of an author is defined as follows: Paul Erdős himself has $\mathbf{n}_{E}=0$; people who have written a joint paper with Paul Erdős have $\mathbf{n}_{E}=1$; and their co-authors, with Erdős number not yet defined, have $\mathbf{n}_{E}=2$; etc.

Often on the home pages of people interested in or related to combinatorics we find the statement:

My Erdös number is ...

Patrick Ion (Mathematical Reviews) and Jerry Grossman (Oakland University) collected the related data (Grossman and Ion, 1995, Grossman, 1996) and made them available at the URL:

http://www. oakland.edu/〜grossman/erdoshp.html

These data can be represented as a graph called the Erdós collaboration graph $-\mathcal{E}=$ $(V, E)$. The set of its vertices $V$ consists of known authors with $\mathbf{n}_{E} \leq 2$, and its edges connect two authors, if they wrote a joint paper, and at least one of them has $\mathbf{n}_{E} \in\{0,1\}$ — the data about collaboration among authors with $\mathbf{n}_{E}=2$ are not (yet?) available.

The data are updated annually. Table 1 shows the 'growth' of the Erdôs collaboration graph.

By removing Paul Erdős himself and connections to him from the graph $\mathcal{E}$ we get the truncated Erdós collaboration graph $\mathcal{E}^{\prime}$. The last, 1999 edition of this graph contains 6100 vertices and 9939 edges. 
Table 1: The growth of Erdős collaboration graph

\begin{tabular}{|r|r|r|r|r|r|r|}
\hline & \multicolumn{2}{|c|}{$\mathbf{n}_{E}=0,1$} & \multicolumn{2}{c|}{$\mathbf{n}_{E}=2$} & \multicolumn{2}{c|}{ Total } \\
\hline Year & $\left|V_{01}\right|$ & $\left|E_{01}\right|$ & $\left|V_{2}\right|$ & $\left|E_{2}\right|$ & $|V|$ & $|E|$ \\
\hline 1997 & 473 & 1786 & 5016 & 7658 & 5489 & 9444 \\
1998 & 486 & 1866 & 5337 & 8124 & 5823 & 9990 \\
1999 & 493 & 1909 & 5608 & 8522 & 6101 & 10431 \\
\hline
\end{tabular}

The names of authors with $\mathbf{n}_{E}=1$ are written in capitals and the names of authors with $\mathbf{n}_{E}=2$ are only capitalized.

We used program Pajek to make some analyses and get layouts of selected parts of Erdős collaboration graph. Pajek is a program, for Windows, for analysis and visualization of large networks (Batagelj and Mrvar, 1998). It is freely available for noncommercial use at:

http://vlado.fmf.uni-lj.si/pub/networks/pajek/

\section{Some basic analyses}

In Table 2 some basic statistics about the number of co-authors - vertex degrees in Erdős collaboration graph $\mathcal{E}$ are presented.

Table 2: Basic statistics on degrees in Erdős collaboration graph

\begin{tabular}{|r|r|r|r|}
\hline & $\mathbf{n}_{E}=1$ & $\mathbf{n}_{E} \in\{0,1\}$ & $\mathbf{n}_{E}=2$ \\
\hline minimum & 1 & 1 & 1 \\
median & 18 & 18 & 1 \\
average degree & 24.08 & 25.03 & 1.52 \\
maximum & 277 & 492 & 18 \\
maximizer & Harary & Erdős & Lesniak \\
\hline
\end{tabular}

There exist 17 connected components in $\mathcal{E}^{\prime}$. One of them is very large (it contains 6045 authors), others are smaller (they contain 12 authors at most, see Figure 1).

The diameter of the large component in graph $\mathcal{E}^{\prime}$ is 12 with 3 diametric pairs of vertices

( Jakob, Matthias : An, Chung Ming )

( Jakob, Matthias : Corsten, L. C. A. )

( Jakob, Matthias : Stux, Ivan E. ) 


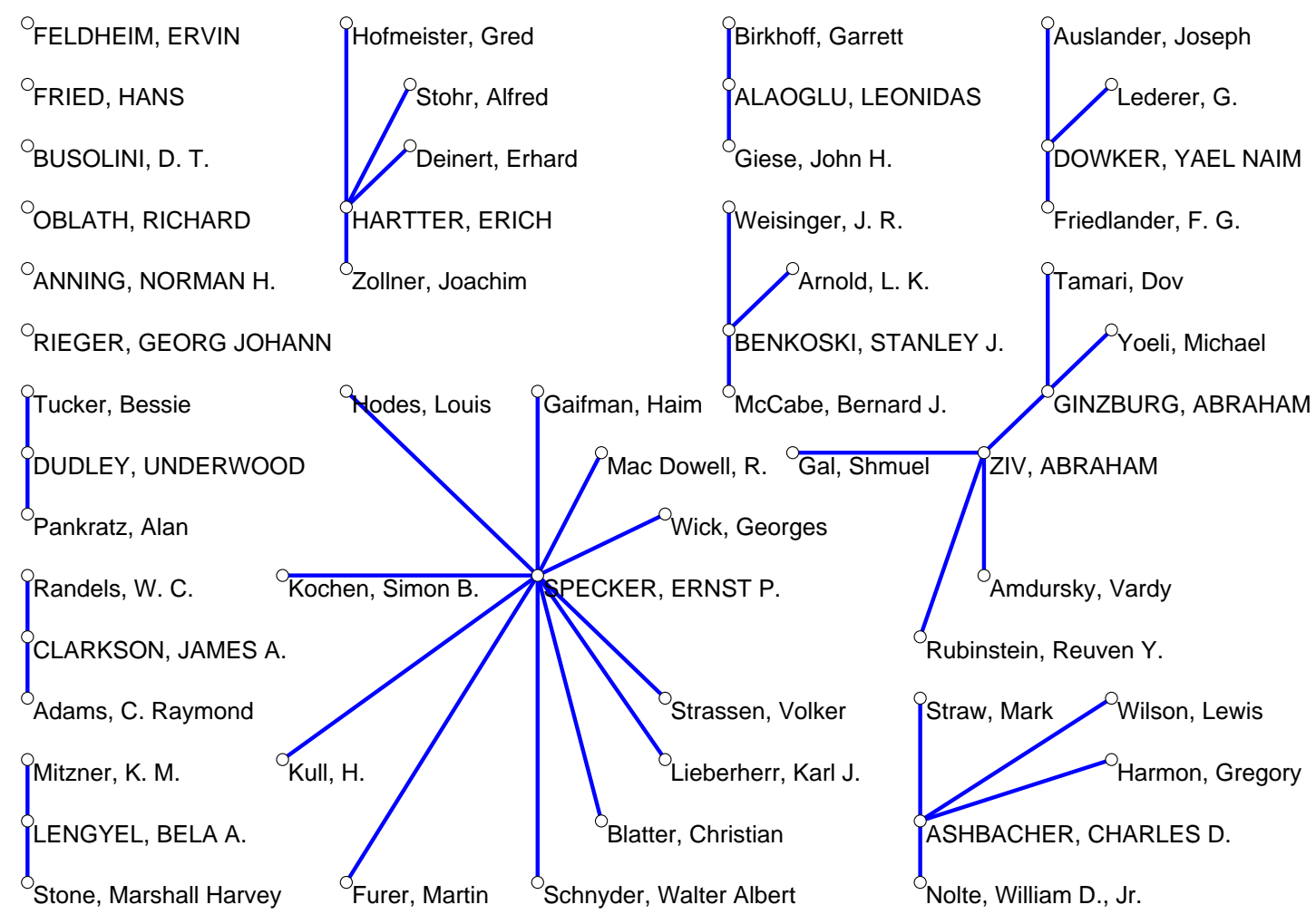

Figure 1: Small components. 


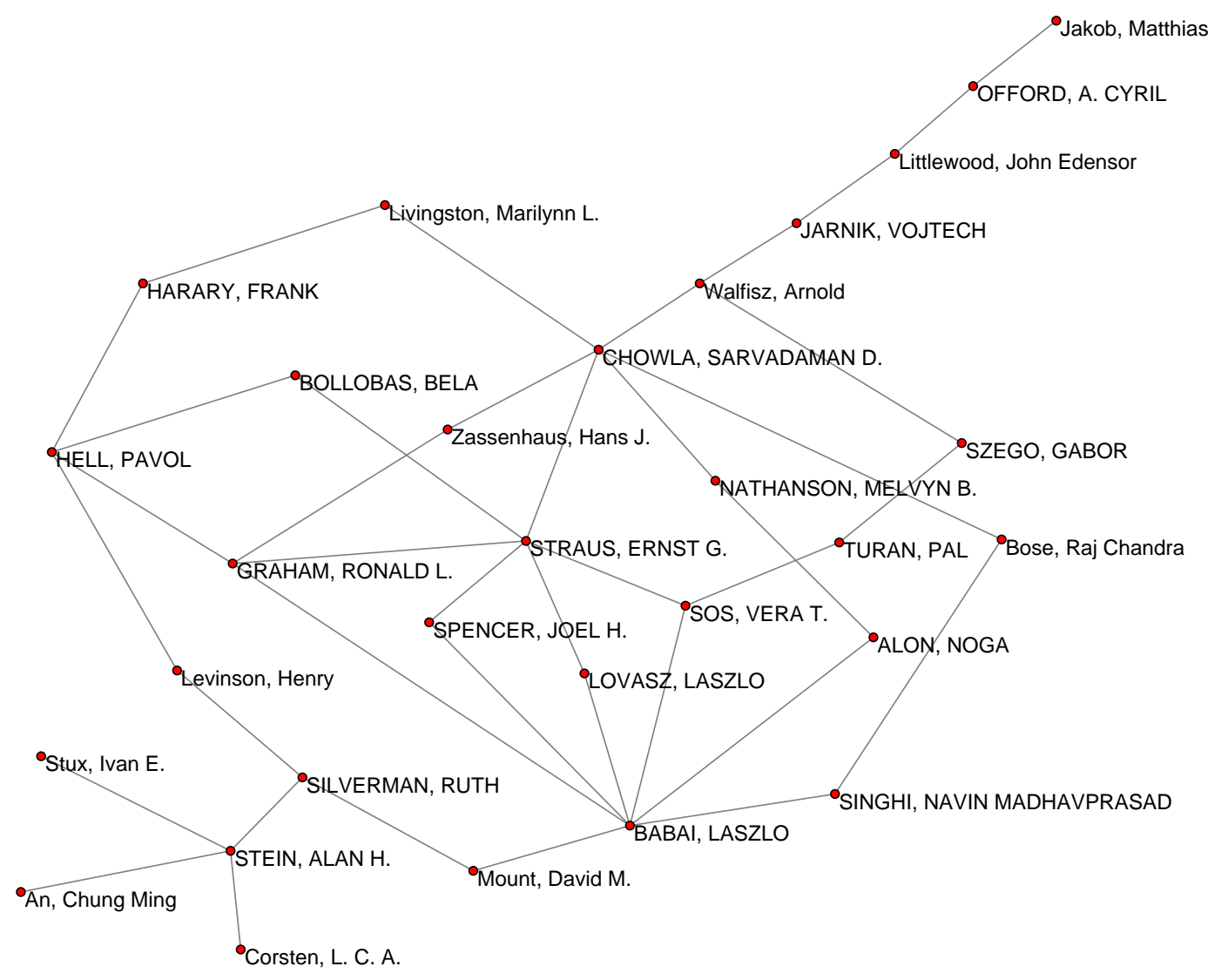

Figure 2: Diametric Geodesics. 
Table 3: Top ten authors according to number of co-authors

\begin{tabular}{|l|r|r|}
\hline Author & No. of co-authors & core \\
\hline ERDOS, PAUL & 492 & 10 \\
HARARY, FRANK & 277 & 10 \\
ALON, NOGA & 168 & 10 \\
SHELAH, SAHARON & 146 & 7 \\
GRAHAM, RONALD L. & 126 & 10 \\
COLBOURN, CHARLES J. & 121 & 7 \\
KLEITMAN, DANIEL J. & 117 & 10 \\
ODLYZKO, ANDREW M. & 113 & 8 \\
TUZA, ZSOLT & 107 & 10 \\
HOFFMAN, ALAN J. & 93 & 7 \\
\hline
\end{tabular}

The corresponding geodesic subgraph is presented in Figure 2.

The top ten authors according to the number of co-authors are presented in Table 3. Frank Harary and Noga Alon, the two authors with the highest degree in $\mathcal{E}^{\prime}$, did not (?) write an article together. But there exist 15 authors with whom both of them are coauthors. The common co-authors are:

$\begin{array}{ll}\text { ERDOS, PAUL } & \text { TROTTER, WILLIAM T., JR. } \\ \text { BOLLOBAS, BELA } & \text { TUZA, ZSOLT } \\ \text { DUKE, RICHARD A. } & \text { Akiyama, Jin } \\ \text { FAUDREE, RALPH J. } & \text { Brualdi, Richard A. } \\ \text { GRAHAM, RONALD L. } & \text { Dewdney, Alexander Keewatin } \\ \text { NESETRIL, JAROSLAV } & \text { Fellows, Michael R. } \\ \text { RODL, VOJTECH } & \text { Karp, Richard M. } \\ \text { THOMASSEN, CARSTEN } & \text { Welsh, Dominic J. A. }\end{array}$

The distributions of distances of other authors from Harary and Alon are given in Table 4. We see that the Alon's co-authors are more collaborative.

\section{Cores}

Let $G=(V, E)$ be a graph. The notion of core was introduced by Seidman (1983). A maximal subgraph $H_{k}=(W, E \mid W)$ induced by the set $W \subseteq V$ is a $k$-core, or core of order $k$, iff $\forall v \in W: \operatorname{deg}_{H}(v) \geq k$, see Figure 3. The core of maximum order is also called the main core. The cores have two important properties:

- The cores are nested: $i<j \Longrightarrow H_{j} \subseteq H_{i}$ 
Table 4: Distributions of distances from Harary and Alon

\begin{tabular}{|c|r|r|}
\hline Distance & from Harary & from Alon \\
\hline 0 & 1 & 1 \\
1 & 276 & 167 \\
2 & 938 & 1124 \\
3 & 2757 & 2764 \\
4 & 1514 & 1416 \\
5 & 538 & 473 \\
6 & 12 & 99 \\
7 & 9 & 1 \\
\hline Sum & 6045 & 6045 \\
\hline$\infty$ & 55 & 55 \\
\hline Average & 3.193 & 3.199 \\
\hline
\end{tabular}

- There exists an efficient algorithm of order $O(|E|)$ for determining the cores (Batagelj, Mrvar and Zaveršnik, 1999).

We denote the neighborhood of vertex $v \in V$ by $N(v)$ :

$$
N(v)=\{u \in V:(v: u) \in E\}
$$

and the rooted neighborhood of vertex $v \in V$ by $N^{+}(v)$ :

$$
N^{+}(v)=N(v) \cup\{v\}
$$

In $\mathcal{E}$ the main core is of order 10 , and of order 9 in $\mathcal{E}^{\prime}$. In Table 5 the distribution in $\mathcal{E}$ of number of authors in $k$-cores (second column), and the distributions of number of coauthors in cores for selected members of the main core, are given. The authors belonging to the main core and some of their characteristics are presented in Table 6 , where $\overline{\mathrm{deg}}$ is the average degree of all co-authors.

$$
\overline{\operatorname{deg}}(v)=\left\{\begin{array}{cl}
0 & N(v)=\emptyset \\
\frac{1}{|N(v)|} \sum_{u \in N(v)} \operatorname{deg}(u) & \text { otherwise }
\end{array}\right.
$$

and $\overline{c o r e}$ is the average core number of all co-authors.

$$
\overline{\operatorname{core}}(v)=\left\{\begin{array}{cl}
0 & N(v)=\emptyset \\
\frac{1}{|N(v)|} \sum_{u \in N(v)} \operatorname{core}(u) & \text { otherwise }
\end{array}\right.
$$




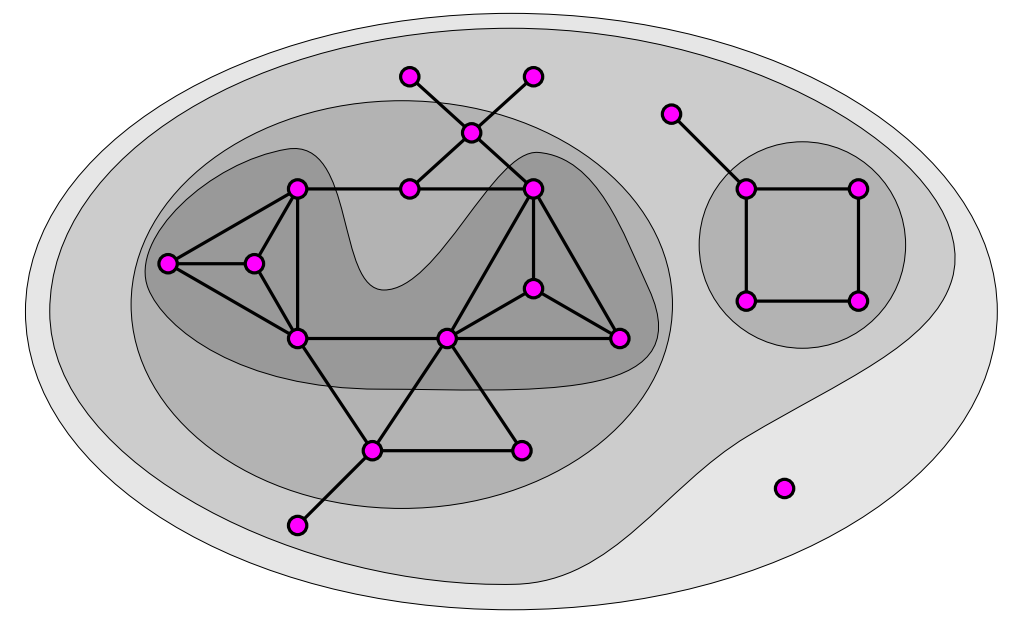

Figure 3: 0, 1, 2 and 3 core.

Table 5: Distribution of number of co-authors in cores

\begin{tabular}{|c|r|r|r|r|r|r|r|r|}
\hline core & No. of authors & ERDỎS & HARARY & ALON & Lesniak & RODL & SIMON. & LEHEL \\
\hline 10 & 37 & 35 & 14 & 18 & 10 & 19 & 12 & 16 \\
9 & 14 & 12 & 4 & 2 & 3 & 7 & 2 & 1 \\
8 & 27 & 19 & 4 & 11 & 1 & 7 & 3 & 0 \\
7 & 73 & 45 & 16 & 15 & 2 & 13 & 3 & 1 \\
6 & 96 & 50 & 17 & 8 & 1 & 4 & 2 & 2 \\
5 & 178 & 94 & 14 & 8 & 0 & 4 & 2 & 5 \\
4 & 231 & 89 & 11 & 19 & 1 & 4 & 2 & 1 \\
3 & 410 & 71 & 27 & 22 & 0 & 8 & 0 & 3 \\
2 & 853 & 62 & 38 & 23 & 0 & 12 & 2 & 2 \\
1 & 4182 & 15 & 132 & 42 & 0 & 10 & 1 & 1 \\
\hline Sum & 6101 & 492 & 277 & 168 & 18 & 88 & 29 & 32 \\
\hline Average & 1.76 & 4.88 & 2.98 & 4.22 & 8.83 & 5.89 & 7.52 & 7.22 \\
\hline
\end{tabular}


Table 6: Authors and number of their co-authors in the main core, total number of coauthors, average core and average degree of all their co-authors, and their collaborativeness

\begin{tabular}{|l|r|r|r|r|r|}
\hline Author & Co-authors & All co-authors & $\overline{\text { core }}$ & $\overline{\text { deg }}$ & coll \\
\hline ERDOS PAUL & 35 & $* 492$ & 4.88 & 24.08 & 2.05 \\
FAUDREE, RALPH J. & 19 & 51 & 6.33 & 38.63 & 1.58 \\
GRAHAM, RONALD L. & 19 & 126 & 4.94 & 26.64 & 2.03 \\
RODL, VOJTECH & 19 & 88 & 5.89 & 32.53 & 1.70 \\
ALON, NOGA & 18 & $* 168$ & 4.22 & 17.63 & $* 2.37$ \\
GYARFAS, ANDRAS & 18 & 41 & 6.90 & 40.85 & 1.45 \\
JACOBSON, MICHAEL S. & 17 & 55 & 5.87 & 30.60 & 1.70 \\
TUZA, ZSOLT & 17 & 107 & 4.21 & 22.73 & $* 2.38$ \\
CHUNG, FAN RONG K. & 16 & 81 & 5.12 & 30.79 & 1.95 \\
GOULD, RONALD J. & 16 & 37 & 6.73 & 35.00 & 1.49 \\
FUREDI, ZOLTAN & 16 & 65 & 5.95 & 36.45 & 1.68 \\
LEHEL, JENO & 16 & 32 & $* 7.22$ & 42.69 & 1.39 \\
SCHELP, RICHARD H. & 16 & 42 & 6.21 & 33.12 & 1.61 \\
SPENCER, JOEL H. & 16 & 67 & 6.10 & 38.99 & 1.64 \\
BURR, STEFAN ANDRUS & 15 & 29 & 7.14 & $* 58.58$ & 1.40 \\
SZEMEREDI, ENDRE & 15 & 68 & 5.87 & 30.13 & 1.70 \\
HARARY, FRANK & 14 & $* 277$ & 2.98 & 9.62 & $* 3.36$ \\
WEST, DOUGLAS B. & 14 & 81 & 4.14 & 20.10 & $* 2.42$ \\
CHARTRAND, GARY & 13 & 81 & 5.27 & 23.33 & 1.90 \\
LOVASZ, LASZLO & 13 & 91 & 4.74 & 23.30 & 2.11 \\
NESETRIL, JAROSLAV & 13 & 65 & 5.31 & 33.12 & 1.88 \\
PACH, JANOS & 13 & 78 & 4.88 & 25.33 & 2.05 \\
BABAI, LASZLO & 12 & 75 & 4.99 & 27.32 & 2.01 \\
FRANKL, PETER & 12 & 64 & 5.41 & 33.67 & 1.85 \\
SIMONOVITS, MIKLOS & 12 & 29 & $* 7.52$ & $* 50.76$ & 1.33 \\
TROTTER, WILLIAM T., JR. & 12 & 54 & 5.48 & 39.15 & 1.82 \\
OELLERMANN, ORTRUD R. & 11 & 40 & 6.63 & 38.45 & 1.51 \\
SOS, VERA T. & 11 & 37 & 6.84 & 47.00 & 1.46 \\
BOLLOBAS, BELA & 10 & 78 & 4.92 & 30.10 & 2.03 \\
CHEN, GUANTAO & 10 & 59 & 5.76 & 33.83 & 1.74 \\
GODDARD, WAYNE D. & 10 & 68 & 6.10 & 29.56 & 1.64 \\
HAJNAL, ANDRAS & 10 & 50 & 5.74 & 36.66 & 1.74 \\
KLEITMAN, DANIEL J. & 10 & 19 & 4.03 & 18.11 & $* 2.48$ \\
KUBICKA, EWA MARIE & 10 & 7.11 & $* 64.95$ & 1.41 \\
KUBICKI, GRZEGORZ & 10 & 78 & $* 8.83$ & 34.89 & 1.13 \\
Lesniak, Linda M. & 10 & 5.10 & 34.68 & 1.96 \\
ROUSSEAU, CECIL CLYDE & & &
\end{tabular}


Table 7: Top ten most collaborative authors

\begin{tabular}{r|l|r|}
\hline & author & coll \\
\hline 1 & HARARY, FRANK & 3.358 \\
2 & SHELAH, SAHARON & 3.106 \\
3 & HOFFMAN, ALAN J. & 3.056 \\
4 & SALAT, TIBOR & 2.674 \\
5 & CHUI, CHARLES KAM-TAI & 2.538 \\
6 & JANSON, SVANTE & 2.537 \\
7 & FISHBURN, PETER C. & 2.521 \\
8 & FRAENKEL, AVIEZRI S. & 2.514 \\
9 & VAN LINT, JACOBUS HENDRICUS & 2.503 \\
10 & KRANTZ, STEVEN GEORGE & 2.493 \\
\hline
\end{tabular}

The authors with the highest values of $\overline{\mathrm{deg}}$ and $\overline{\text { core }}$ are indicated by a star.

We have to be very careful in interpretation of $\overline{\mathrm{deg}}$ and core. Their high values imply that a 'central' author is mainly collaborating with other 'central' authors. Therefore we propose as a measure of collaborativeness the quantity

$$
\operatorname{coll}(v)=\frac{\operatorname{core}(v)}{\overline{\operatorname{core}}(v)}
$$

that measures the openness of author $v$ towards 'peripheral' authors. If core $(v)=0$, also $\operatorname{coll}(v)=0$.

The most collaborative authors in the main core are Frank Harary, Daniel Kleitman, Douglas West, Zsolt Tuza and Noga Alon. But, it turns out that among the top ten most collaborative authors Frank Harary is the only one from the main core (see Table 7).

Note that this is valid only relatively to the graph $\mathcal{E}$ since for authors with $\mathbf{n}_{E}=2$ their core numbers are underestimated, because of incomplete data about their collaboration.

\section{Lords}

We call 'lords' vertices that have 'strong influence' to their neighborhoods. At the beginning we assign to each vertex its degree as its initial power. The final distribution of power is the result of 'transferring' the power from weaker to stronger vertices.

To determine this distribution we order vertices in the increasing order according to their degrees and in this order we deal the power of the current vertex to its stronger neighbors proportionally. The result of applying this procedure on $\mathcal{E}^{\prime}$ is given in Table 8 .

In an alternative version of this procedure each vertex obtains equal initial power 1 , and the vertex is considered stronger if it has greater power or, in the case of equal powers, 
Table 8: Lords

\begin{tabular}{r|l|r|}
\hline & Author & Power \\
\hline 1 & HARARY, FRANK & 7043.46 \\
2 & ALON, NOGA & 6773.39 \\
3 & RUBEL, LEE A. & 1643.83 \\
4 & COLBOURN, CHARLES J. & 1151.59 \\
5 & SHELAH, SAHARON & 753.12 \\
6 & KAC, MARK & 252.39 \\
7 & CHUI, CHARLES KAM-TAI & 235.28 \\
8 & MAULDIN, R. DANIEL & 214.22 \\
9 & JOO, ISTVAN & 198.73 \\
10 & BRENNER, JOEL LEE & 169.29 \\
\hline
\end{tabular}

if it has greater degree. Again, we obtain for 'lords' a permutation of the same authors. In $\mathcal{E}$ the only lord is Paul Erdôs.

\section{Blockmodeling}

To uncover the internal structure of the main core of $\mathcal{E}^{\prime}$ we applied pre-specified blockmodeling (Batagelj, 1997, Batagelj, Ferligoj and Doreian, 1998) to it. As a block model we selected:

- cliques as diagonal blocks,

- complete or empty out-diagonal blocks.

We obtained a partition into 9 clusters - the smallest contains only 1 author, the largest 8 authors. All clusters are cliques.

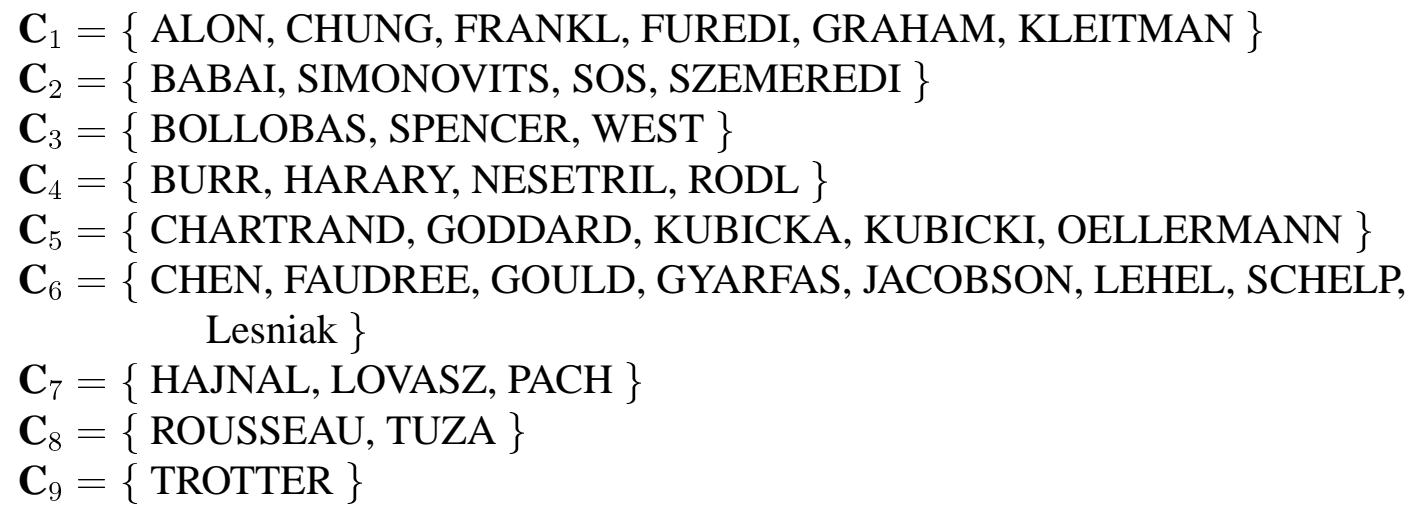




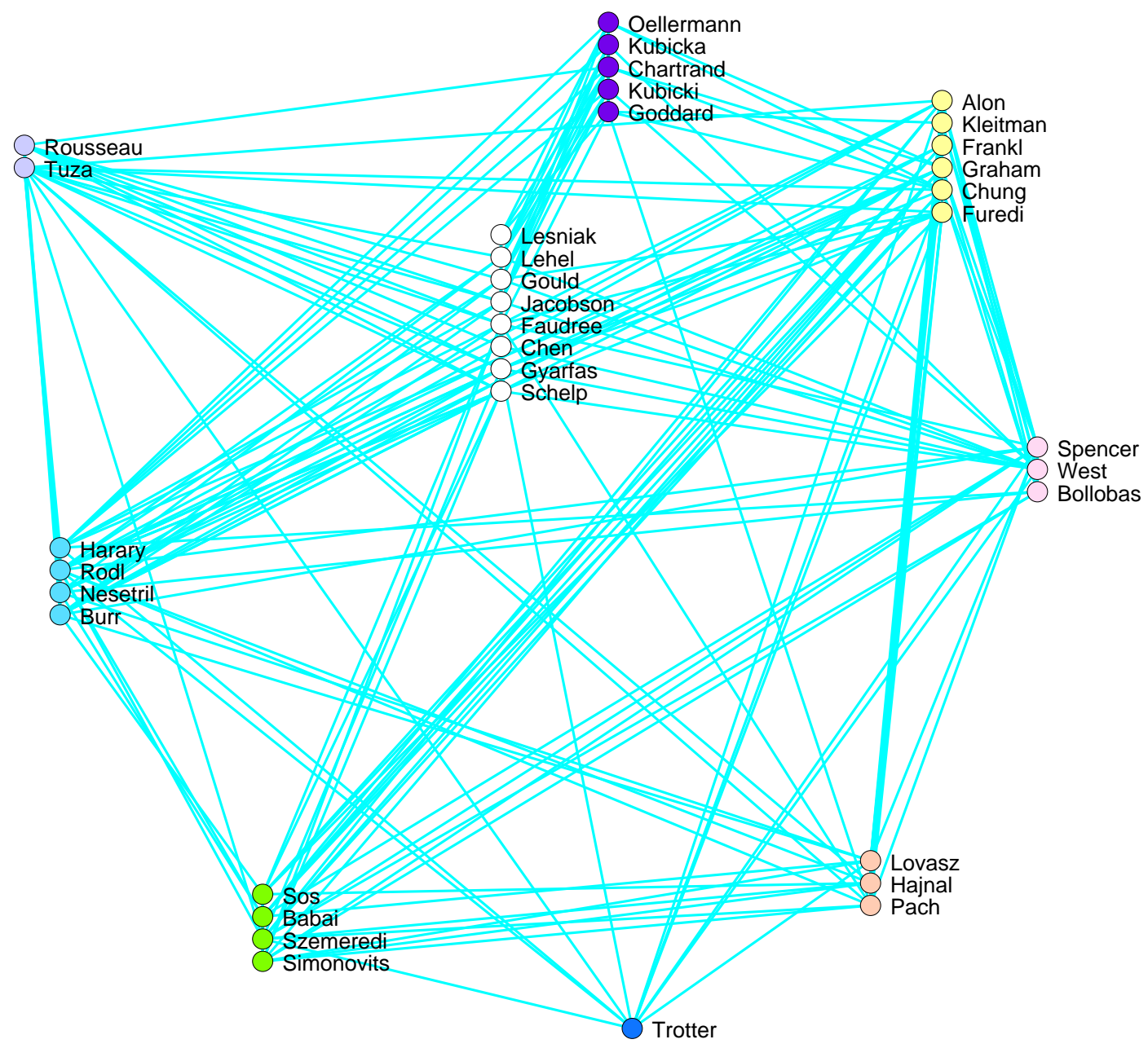

Figure 4: Cliques of the main core. 
ALON, NOG CHUNG, FA FRANKL, $P$ FUREDI, Z

GRAHAM, $R$ KLEITMAN, BABAI, LA SIMONOVIT SOS, VERA SZEMEREDI BOLLOBAS, SPENCER, WEST, DOU BURR, STE HARARY, F NESETRIL, RODL, VOJ CHARTRAND GODDARD, KUBICKA, KUBICKI, OELLERMAN CHEN, GUA FAUDREE, GOULD, RO GYARFAS, JACOBSON, LEHEL, JE SCHELP, R Lesniak, HAJNAL, A LOVASZ, L PACH, JAN ROUSSEAU, TUZA, ZSO TROTTER,

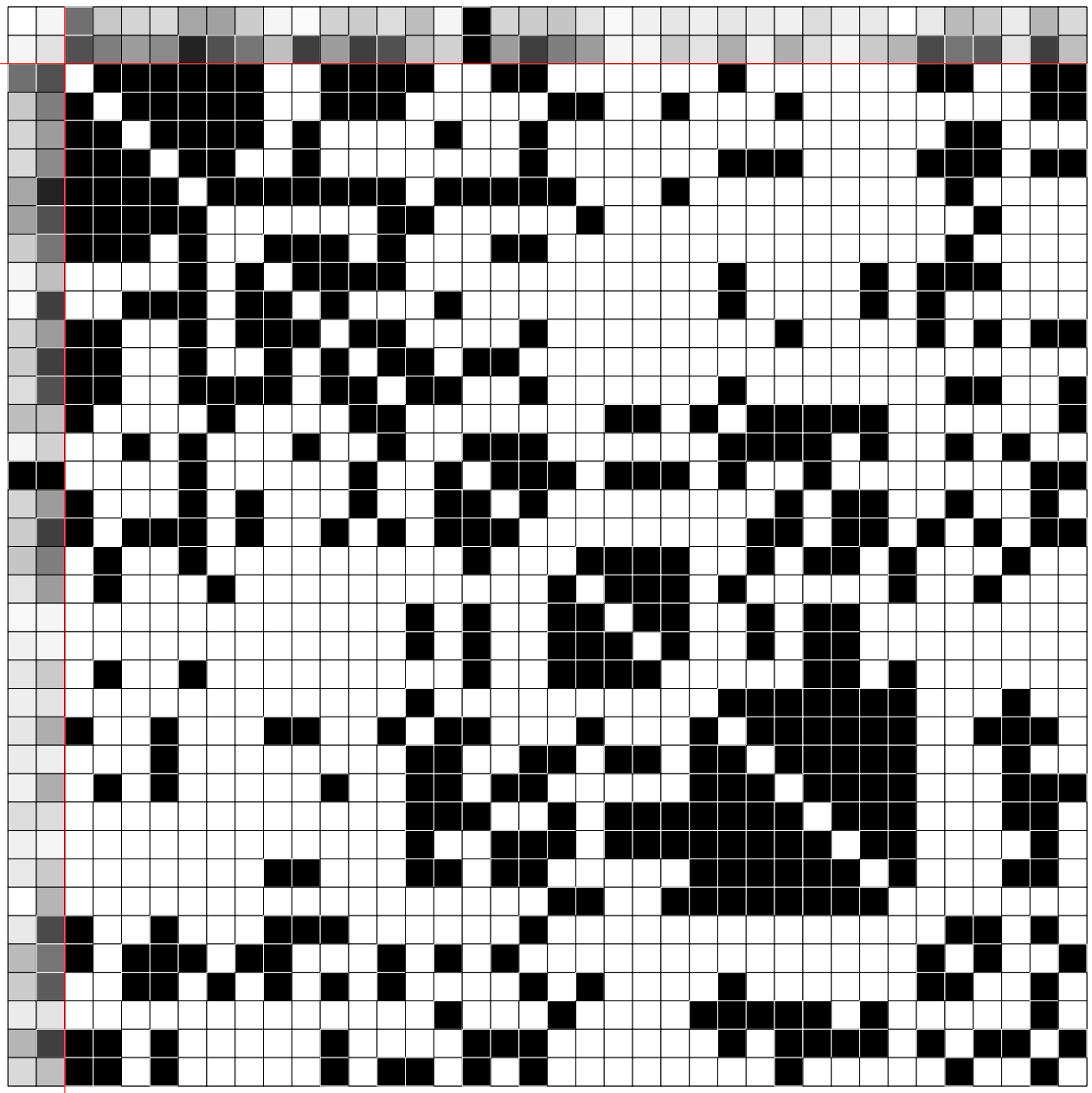

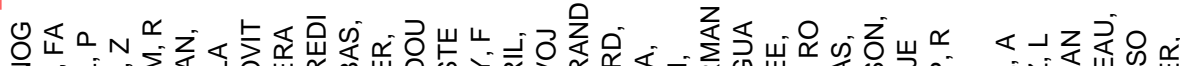

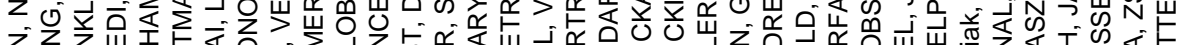

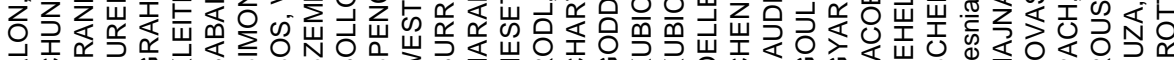

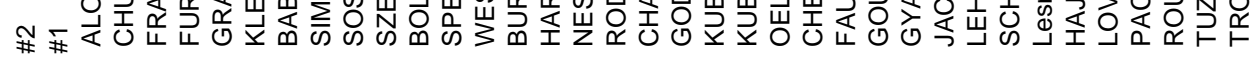

Figure 5: The main core matrix with context. 
Figures 4 and 5 represent the blockmodeling results. In Figure 4 a view of 3D layout of the main core subgraph is given. A kinemage file (for Mage viewer) with the same layout is available at:

$$
\text { http://vlado.fmf.uni-lj.si/pub/networks/doc/erdos/ }
$$

In Figure 5 an alternative visualization of this result, based on adjacency matrix (with context) reordered according the obtained clustering, is displayed. The first and the second row / column show the intensity (inside-cluster degree normalized with maximal insidecluster degree) of collaboration of authors of the main core with the remaining authors with $\mathbf{n}_{E}=2$ and $\mathbf{n}_{E}=1$.

Coloring $\mathbf{C}_{6}$ with 8 colors, it is easy to extend this coloring to the main core and further to the remaining part of $\mathcal{E}^{\prime}$. Therefore $\chi\left(\mathcal{E}^{\prime}\right)=8$, and, since $\mathbf{n}_{E}$ (Lesniak) $=2$, $\chi(\mathcal{E}) \in\{8,9\}$. Till now we didn't succeed to find an 8-coloring.

On cores we can build an efficient procedure for coloring large graphs that combines an exact procedure used on the main core, if it is small enough, and sequential coloring to extend the obtained core coloring to the remaining graph. The coloring order of vertices is determined by ordering them in decreasing order according to pairs $(\operatorname{core}(v), \operatorname{deg}(v))$.

\section{Clustering}

Another approach to analyze the graph is to introduce a dissimilarity $d$ into the set $V$, or its subset, and apply some of multivariate techniques to it. Examples of such dissimilarities are $(\oplus$ denotes the symmetric difference and $D=\max \{|N(u)|+|N(v)|: u \neq v ; u, v \in$ $V\})$ :

$$
\begin{aligned}
& d_{1}(u, v)=\frac{|N(u) \oplus N(v)|}{D} \\
& d_{2}(u, v)=\frac{|N(u) \oplus N(v)|}{|N(u) \cup N(v)|} \\
& d_{3}(u, v)=\frac{|N(u) \oplus N(v)|}{|N(u)|+|N(v)|} \\
& d_{4}(u, v)=\frac{\max (|N(u) \backslash N(v)|,|N(v) \backslash N(u)|)}{\max (|N(u)|,|N(v)|)}
\end{aligned}
$$

These dissimilaries are in fact (semi)distances known in data analysis (some after transformation $d=1-s$ from similarity $s$ into dissimilarity $d$ ) as dissimilarities of: $d_{1}-$ Hamming, Kendall, Sokal-Michner; $d_{2}-$ Jaccard; $d_{3}$ - Dice, Czekanowski; $d_{4}-$ BraunBlanquet (Batagelj and Bren, 1995).

In the case $N(u)=N(v)=\emptyset$ we set for all four dissimilarities $d(u, v)=1$. We obtain a parallel set of dissimilarities $d_{1}^{+}, d_{2}^{+}, d_{3}^{+}$and $d_{4}^{+}$by replacing in the above definitions neigborhoods $N$ with rooted neighborhoods $N^{+}$. 
Groups/clusters of similar units can be obtained by methods of cluster analysis (Gordon, 1981). We determined $d_{2}^{+}$on $\{8,9,10\}$-core considering all authors from $\mathcal{E}$ and applied hierarchical clustering, Ward's method to it. Again, because of incomplete data for authors with $\mathbf{n}_{E}=2$, their dissimilarities are relative to $\mathcal{E}$. The obtained dendrogram (clustering tree) is given in Figure 6.

\section{Final remarks}

In the paper we presented some possible approaches to analysis of large networks and applied them to the Erdős collaboration graph. Because of incomplete data for authors with $\mathbf{n}_{E}=2$ the results are valid only for authors with $\mathbf{n}_{E}=1$, or they should be interpreted for each group separately.

For better interpretation of the obtained results and for further analyses additional information about authors (year of birth, subjects of interest, geographic location, nationality, ...) and papers connecting them (number of papers, list of MR categories, ...) would be needed.

The (truncated) Erdős collaboration graph in Pajek format and some files with results are available at URL:

http://vlado.fmf.uni-lj.si/pub/networks/doc/erdos/

This paper is an elaborated version of the talk presented at the Fourth Slovene International Conference in Graph Theory, June 28 - July 2, 1999, Bled, Slovenia.

Acknowledgment: This work was supported by the Ministry of Science and Technology of Slovenia, Project J1-8532. 
LOVASZ,LAS

SPENCER,JO

WINLLBAS,B

WINKLER,PE

WEST,DOUGL

PACH,JANOS

UUZA,ZSOLT

ERDOS,PAUL

BABAI,LASZ

SZEGEDY,MA

NESETRIL,J

RODL, VOJTE

SIMONOVITS

SOS,VERA T

ROTHSCHILD

HAJNAL,AN

MILNER,ERI

SAUER,NORB

Brightwell

Duffus,Dwi

KIERSTEAD,

TROTTER,WI

GYORI,ERVI

PYBER,LASZ

KOSTOCHKA,

LUCZAK,TOM

BONDY,JOHN

CHVATAL,VA

THOMASSEN,

IARARY FRA

SCHWENK,AL

AJTAI,MIKL

KOMLOS,JAN

ALON,NOGA

KLEITMAN,D

LINIAL,NAT

SAKS,MICHA

RANKL,PET

FUREDI,ZOL

SERESS,AKO

FISHBURN,P

ODLYZKO,AN

CHUNG,FAN

GRAHAM,RON

Erdos,Pete

Katona,Gyu

Seymour,Pa

ENTRINGER

SZEKELY,LA

Pudlak,Pav

Turan,Gyor

Hajnal,Pet

HENNING,MI

SWART,HEND

CHARTRAND,

OELLERMANN

ALAVI,YOUS

LICK,DON R

Saba,Farro

Lesniak

KUBICKA,EW

KUBICKI, ER

GOULD, RONA

JACOBSON,M

CHEN,GUANT

GYARFAS,AN

LEHEL,JENO

FAUDREE,RA

SCHELP,RIC

BURR,STEFA

ROUSSEAU,C

SCHUSTER,S

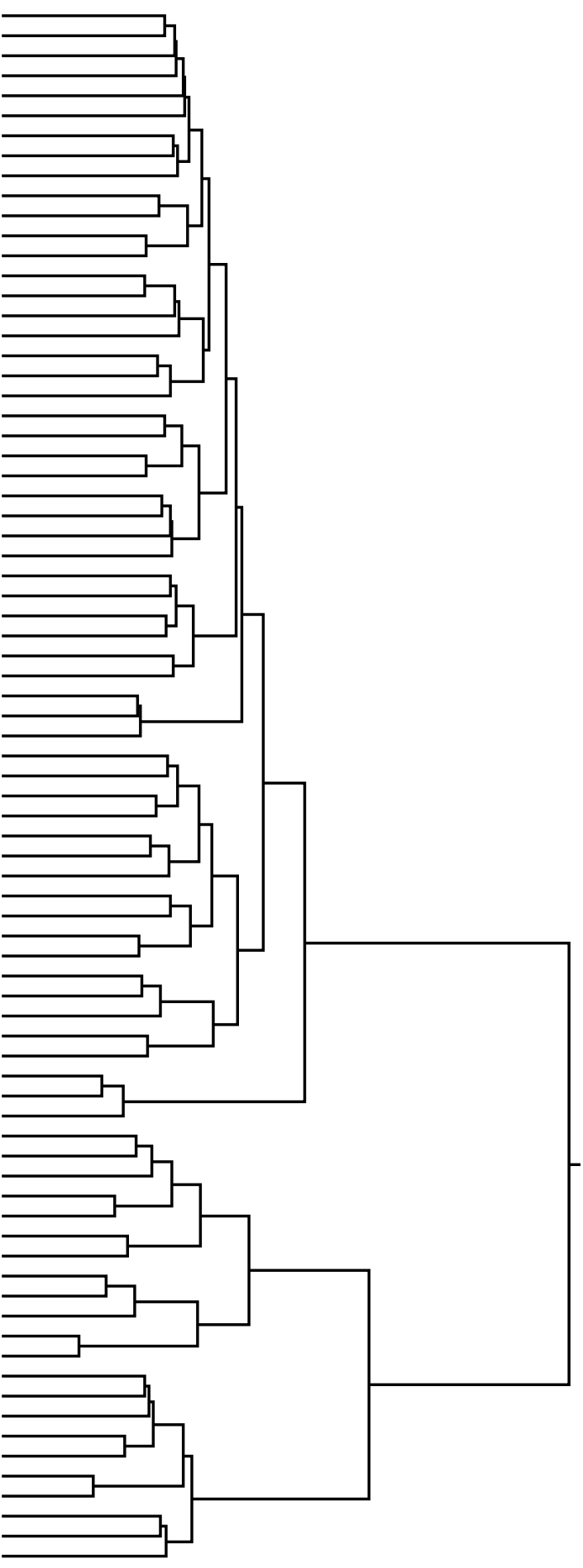

Figure 6: $\{8,9,10\}$-core clustering. 


\section{References}

Batagelj, V., 1997. Notes on Blockmodeling. Social Networks 19, 143-155.

Batagelj, V., Bren, M., 1995. Comparing Resemblance Measures. Journal of Classification 12(1), 73-90.

Batagelj, V., Ferligoj, A., and Doreian, P., 1998. Fitting Pre-Specified Blockmodels, in Data Science, Classification, and Related Methods, Eds., C. Hayashi, N. Ohsumi, K. Yajima, Y. Tanaka, H. H. Bock, and Y. Baba, Springer-Verlag, Tokyo, 199-206.

Batagelj, V., Mrvar, A., 1998. Pajek - A Program for Large Network Analysis. Connections 21 (2), 47-57.

Batagelj, V., Mrvar, A., Zaveršnik, M., 1999. Partitioning Approach to Visualization of Large Networks. To appear in Proceedings of Graph Drawing '99. LNCS, Springer.

Gordon, A.D., 1981. Classification. Chapman and Hall, London.

Grossman, J.W., Ion, P.D.F., 1995. On a Portion of the Well-Known Collaboration Graph. Proc. 26th Southeastern Inter. Conf. on Combinatorics, Graph Theory and Computing (Boca Raton, FL, 1995), Congr. Numer. 108, 129-131.

Grossman, J.W., 1996. The Erdős Number Project.

http: / / www. oakland.edu/ grossman/erdoshp.html

Seidman, S.B., 1983. Network Structure And Minimum Degree. Social Networks 5, 269-287. 